\title{
The relationship between Norwegian Red heifer growth and their first-lactation test-day milk yield: A field study
}

\author{
K. S. Storli, ${ }^{*}$ G. Klemetsdal, ${ }^{*} H$. Volden, ${ }^{*} \dagger$ and R. Salte*1 \\ *Department of Animal and Aquacultural Sciences, Norwegian University of Life Sciences, NO-1432 Ås, Norway \\ †Tine SA, NO-1431 Ås, Norway
}

\begin{abstract}
Today's Norwegian Red (NR) is markedly different from the one that existed $25 \mathrm{yr}$ ago due to the continuous genetic improvement of economically important traits. Still, current national recommendations on replacement heifer rearing largely are based on results from Danish studies from the late 1980s to the mid 1990s. The objectives of the present study were to gain information on (1) growth and growth profiles of modern NR replacement heifers in commercial dairy herds and (2) how growth during the rearing period affects the heifers' milk yield during their first lactation. To this end, we conducted a field study on 5 high-producing and 5 low-producing commercial dairy farms from each of 3 geographical regions in Norway. On these 30 farms, we combined repeated onsite registrations of growth on all available females from newborn to calving with registrations deriving from the Norwegian Dairy Herd Recording System. Each herd was visited 6 to 8 times over a period of $2 \mathrm{yr}$. At each visit, heart girth circumference on all available young females was measured. Registrations were made on a total of 3,110 heifers. After imposing restrictions on the data, growth parameters were estimated based on information from 536 animals, whereas 350 of these animals had the required information needed to estimate the relationship between growth and test-day milk yield. Our findings pointed toward an optimal ADG of $830 \mathrm{~g} / \mathrm{d}$ from 10 to 15 mo of age that would optimize first-lactation yield of heifers in an average Norwegian dairy herd. The optimum will likely increase from selection over time. Utilizing simple proportionality, the ADG between 5 and $10 \mathrm{mo}$ of age ideally should be $879 \mathrm{~g} / \mathrm{d}$, taking into account the fact that animal growth rate is higher at low ages and that a high prepubertal growth rate had no negative effect on first-lactation yield. When such a rearing practice is used to meet the requirements of today's genetically improved NR heifer, heifers can
\end{abstract}

\footnotetext{
Received September 20, 2016.

Accepted May 11, 2017.

${ }^{1}$ Corresponding author: ragnar.salte@nmbu.no
}

both optimize production in their first lactation and enter the milking herd earlier than the current average age of 24.8 mo.

Key words: heifer, prepubertal growth, postpubertal growth, milk yield

\section{INTRODUCTION}

For dairy farming to remain sustainable, it is imperative to rear replacement heifers in a manner that maximizes their lifetime production in terms of yield and profitability (Brickell et al., 2009). The annual replacement rate in a Norwegian dairy herd is 35 to $40 \%$. Current national recommendations on replacement heifer rearing are still largely based on results from studies on Danish dairy breeds from the late 1980s to the mid 1990s (Foldager and Sejrsen, 1991; Sejrsen and Purup, 1997). The Norwegian Red (NR), the dominant breed in Norway, is a dual-purpose breed that is bred for milk and meat production. Today's NR is markedly different from the one that existed 25 yr ago due to continuous genetic improvement of economically important traits (Geno SA, 2015). It is unclear whether rearing and, in particular, feeding practices have been updated accordingly. The effects of recommended rearing practices on growth rate and subsequent milk yield of modern NR heifers have not been analyzed. The objectives of the present study were to gain information on growth and growth profiles of modern NR replacement heifers in commercial dairy herds and on how growth during the rearing period affects the heifers' milk yield during their first lactation. To this end, we conducted a field study on 5 high-producing and 5 low-producing commercial dairy farms from each of 3 geographical regions in Norway. On these 30 farms, we combined repeated onsite registrations of growth on all available females from newborn to calving with registrations deriving from the Norwegian Dairy Herd Recording System.

\section{MATERIALS AND METHODS}

A total of 30 herds from 3 geographical regions in Norway (mid, southwest, and southeast; Figure 1), 10 
from each region, were selected for the study based on the following criteria: more than 30 cow equivalents, freestall barns, unmodified heifer management from 2010 to 2012, NR as the main breed, membership in the Norwegian Dairy Herd Recording System, and farmers' willingness to commit to the trial. To ensure variation in milk yield, average first-lactation 305-d milk yield in 2010 and 2011 should have been greater than 7,500 $\mathrm{kg}$ of ECM for 5 herds from each region and less than $6,500 \mathrm{~kg}$ of ECM for the other 5 herds from each region.

An advisor from Tine SA (Ås, Norway), the dairy advisory team, visited each herd 6 to 8 times from May 2012 to May 2014. On 2 of these visits, about 1 yr apart, the advisor together with the farmer filled in a question sheet on farm management practices. On each visit, heart girth circumference was measured on all available young females from newborn to calving. Only heifers born into the herd with NR AI sires were included in the data. Twins were excluded. Measurements were conducted by 8 different but equally trained people from the dairy advisory team, with scorer confined by region. The same person performed all measurements within a herd except in one region that experienced a change halfway through the study. In this case, the successor calibrated herself against her predecessor by measuring 10 cows. The total data set included 11,066 quality-controlled heart girth measurements from 3,110 heifers ranging in age from 0 to $1,175 \mathrm{~d}$. Heart girth measurements $(\mathrm{cm})$ were converted to $\mathrm{BW}(\mathrm{kg})$ using the equation applied by Tine SA in their herd management program:

$$
\mathrm{BW}=0.000468816 \times \text { heart girth }{ }^{2.67} .
$$

This model is adapted from Bekkevoll and Helberg (2009), who developed and validated a curvilinear regression model in NR (BW = 108-633 kg; comprising nonpregnant and pregnant animals). We compared the 2 models in an independent study consisting of 80 heifers from the university herd (2-777 d of age; $36-685 \mathrm{~kg}$; 2,909 observations) and found a first-order regression coefficient of 1.0031 between the models. This would mean that for an increase in BW of $100 \mathrm{~kg}$, the models produce a weight difference of only $300 \mathrm{~g}$, demonstrating that the 2 equations give close to identical live weights.

To calculate individual BW (iBW) curves (with model 3), we required all animals to have no fewer than 2 observations. Specifically, we required heifers to have measurements over a period of at least $300 \mathrm{~d}$, with the first measurement taken before $275 \mathrm{~d}$ of age and the last taken after 575 d. Measurements taken after calving were excluded. After imposing these restrictions,

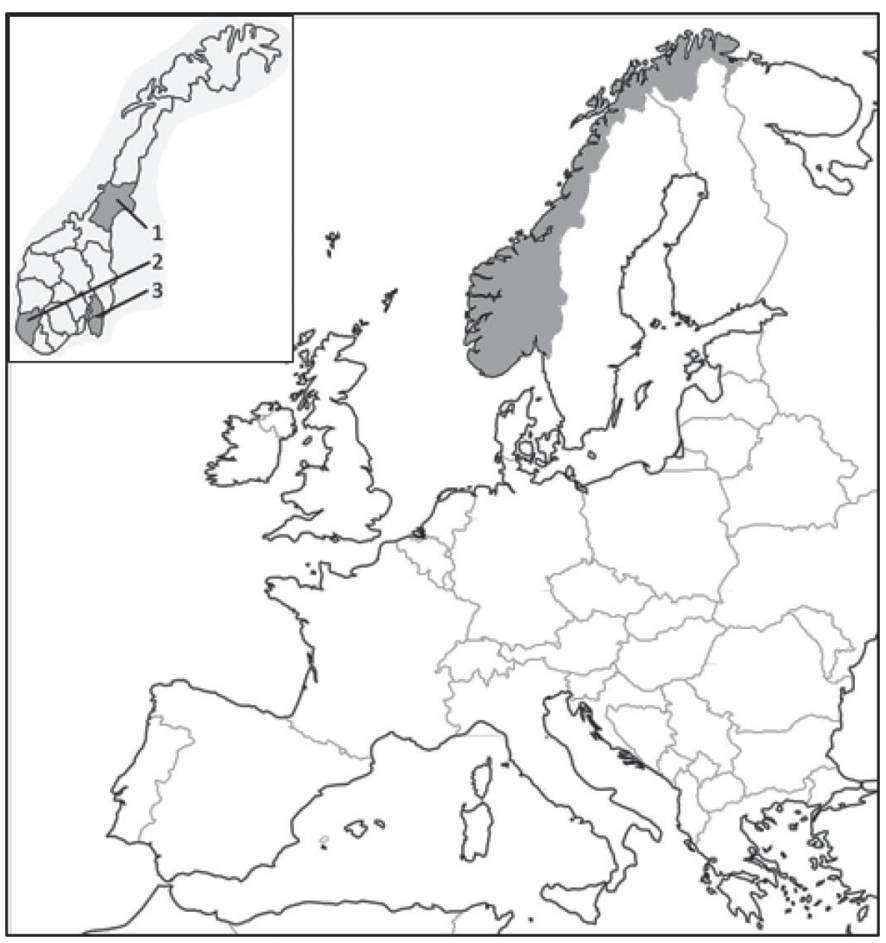

Figure 1. Map of Europe with Norway shown in gray. Inset shows the (1) mid, (2) southwest, and (3) southeast regions. The longitude and latitude of the regional offices of Tine SA, the advisory

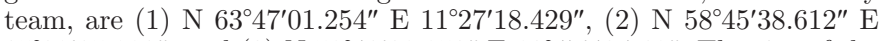
$05^{\circ} 39^{\prime} 05.980^{\prime \prime}$, and (3) N $59^{\circ} 40^{\prime} 09.850^{\prime \prime} \mathrm{E} 10^{\circ} 47^{\prime} 42.769^{\prime \prime}$. The size of the 10 farms in region 1 varied from 31 to 69 cows and production level (first lactation) varied from 5,906 to $7,955 \mathrm{~kg}$ of ECM, in region 2 varied from 32 to 72 cows and 5,622 to $9,650 \mathrm{~kg}$ of ECM, and in region 3 varied from 32 to 114 cows and 5,161 to 8,200 $\mathrm{kg}$ of ECM.

the weight data set contained 3,144 measurements from 536 heifers; the youngest was $17 \mathrm{~d}$ and the oldest was 872 d (Figure 2). Numbers of measurements varied from 2 to 8 per heifer, and $95 \%$ of the animals had 4 or more measurements. All further calculations were based on this data set. All procedures were performed in compliance with the regulatory requirements that apply to the use of animals for scientific purposes in Norway and were approved by the National Animal Research Authority (FOTS ID no. 2955, reference no. 2010/203231).

\section{Herd Mean BW (Model 1)}

The model was used to calculate herd mean BW (hBW) at 4 selected heifer ages: 5, 10, 15, and 21 mo of age. First, the average age at first heart girth measurement was 4.7 mo (thus hBW5). Second, NR females reach puberty at around $280 \mathrm{~kg}$ of $\mathrm{BW}$ and usually between 9 and 11 mo of age (hBW10). Third, historically it has been recommended to breed heifers at 
15 mo of age (hBW15). Finally, 21 mo of age (hBW21) was just before the calving age of the youngest heifers in the data set. Calving ages ranged from 668 to $953 \mathrm{~d}$.

The average $\mathrm{BW}$ in herd $j$ at the given ages and herd BW gain (hBWG; g/d) were calculated from solutions obtained with model 1 :

$$
\begin{gathered}
Y_{i j l}=\mu+P_{i}+\beta_{1} \cdot \mathrm{LEG}_{1}+\beta_{2} \cdot \mathrm{LEG}_{2}+\beta_{0 j} \cdot \mathrm{LEG}_{0} \\
+\cdots+\beta_{4 j} \cdot \mathrm{LEG}_{4}+e_{i j l}
\end{gathered}
$$

where $Y_{i j l}$ is 1 observation of BW $(\mathrm{kg}) ; \mu$ is the overall mean; $P_{i}$ is the fixed effect of the $i$ th person measuring heart girth $(i=1, \ldots, 8) ; \beta_{1}$ and $\beta_{2}$ are fixed regression coefficients of first- and second-order Legendre polynomials (LEG) for the average herd growth curve; $\beta_{0 j}, \ldots, \beta_{4 j}$ are random regression coefficients of order $0, \ldots, 4$ to model the average growth in herd $j$ as a deviation from the average herd growth curve assuming

$$
\sim N\left[\left(\begin{array}{c}
0 \\
\vdots \\
0
\end{array}\right),\left(\begin{array}{ccc}
\sigma_{\beta_{0}}^{2} & \cdots & \sigma_{\beta_{0} \beta_{4}} \\
\vdots & \ddots & \vdots \\
\sigma_{\beta_{0} \beta_{4}} & \cdots & \sigma_{\beta_{4}}^{2}
\end{array}\right)\right]
$$

where the diagonal contains the variances of the coefficients and the off-diagonal the co-variances. Finally, $e$ is a random error term for the $l$ th measurement in herd $j$ modeled with heterogeneous and independent variances for 6 age periods (mo; $<5,5-8,9-12,13-16$, $17-20$, and $>20$ ). Since the 1990s, Legendre polynomials have frequently been used in animal breeding to model nonlinear relationships (e.g., how growth curves change with time; Schaeffer, 2016). The hBWG was calculated from the weight differences between 2 given hBW divided by number of days between the 2 .

\section{Individual Size Within Herd (Model 2)}

Animal size can be split into 2 parameters: size of an individual animal within the herd (iSIZE) and size of an average animal within the herd (hSIZE). To separate hSIZE from iSIZE, model 2 was used:

$$
\begin{aligned}
Y_{i j k l}=\mu+P_{i}+ & \beta_{1} \cdot \mathrm{LEG}_{1}+\beta_{2} \cdot \mathrm{LEG}_{2}+\beta_{0 j} \cdot \mathrm{LEG}_{0} \\
& +\beta_{0 k} \cdot \mathrm{LEG}_{0}+e_{i j k l},
\end{aligned}
$$

where $Y_{i j k l}$ is 1 observation of $\mathrm{BW}(\mathrm{kg}) ; \mu, P_{i}, \beta_{1}, \beta_{2}$, $\mathrm{LEG}_{1}$, and $\mathrm{LEG}_{2}$ are as defined in model $1 ; \beta_{0 j}$ and $\beta_{0 k}$ are random regression coefficients of order 0 for herds and individual heifers, respectively, for both assuming $\sim N\left(0, \sigma_{\beta_{0}}^{2}\right.$ or $\sigma_{\mathrm{hSIZE}}^{2}$ and $\sigma_{\mathrm{iSIZE}}^{2}$, respectively $)$; and $e$ is a random error term for the lth measurement of heifer $k$, defined as in model 1.

\section{iBW (Model 3)}

Model 3 was used to calculate the iBW of heifer $k$ at the chosen ages (iBW5, iBW10, iBW15, and $i B W 21)$ and to derive individual growth rates (iBW gain; iBWG) for the 3 successive periods (iBWG5-10, iBWG10-15, and iBWG15-21):

$$
\begin{gathered}
Y_{i k l}=\mu+P_{i}+\beta_{1} \cdot \mathrm{LEG}_{1}+\beta_{2} \cdot \mathrm{LEG}_{2}+\beta_{0 k} \cdot \mathrm{LEG}_{0} \\
+\cdots+\beta_{2 k} \cdot \mathrm{LEG}_{2}+e_{i k l},
\end{gathered}
$$

where $Y_{i k l}$ is 1 observation of $\mathrm{BW}(\mathrm{kg}) ; \mu, P_{i}, \beta_{1}, \beta_{2}$, $\mathrm{LEG}_{1}$, and $\mathrm{LEG}_{2}$ are as defined in model $1 ; \beta_{0 k}, \ldots, \beta_{2 k}$ are random regression coefficients of order $0, \ldots, 2$ for growth of individual heifers assuming

$$
\sim N\left[\left(\begin{array}{l}
0 \\
\vdots \\
0
\end{array}\right),\left(\begin{array}{ccc}
\sigma_{\beta_{0}}^{2} & \cdots & \sigma_{\beta_{0} \beta_{2}} \\
\vdots & \ddots & \vdots \\
\sigma_{\beta_{0} \beta_{2}} & \cdots & \sigma_{\beta_{2}}^{2}
\end{array}\right)\right]
$$

and $e$ is a random error term for the $l$ th measurement of heifer $k$ defined as in model 1 . The models' bias and mean-squared error were calculated.

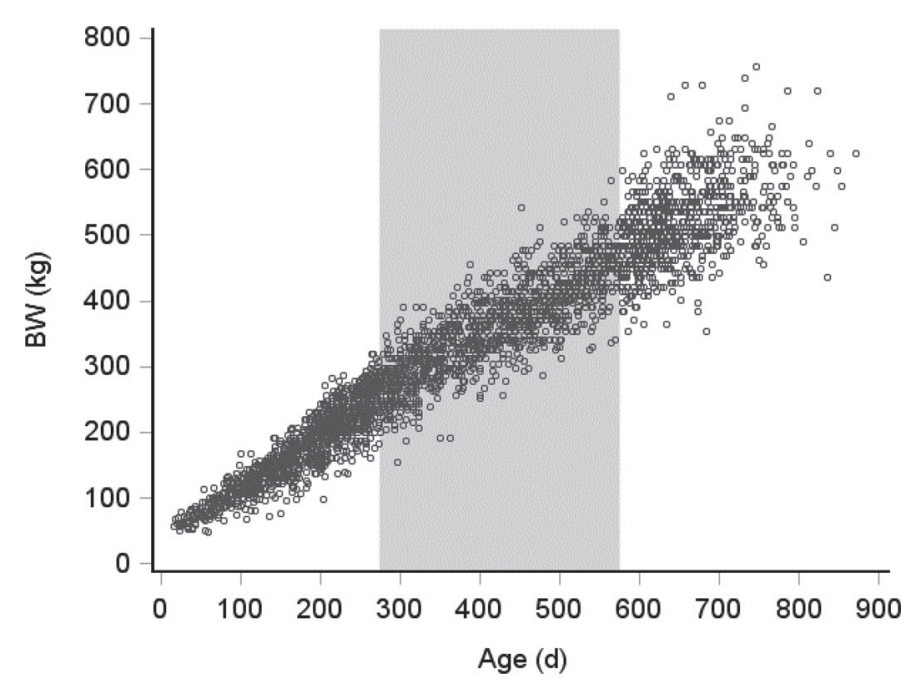

Figure 2. Plot of heifer BW calculated from heart girth measurements $(\mathrm{cm})$. The $X$-axis depicts age (d) when the measurements were taken. All heifers were required to have measurements on both sides of the shaded age interval of $300 \mathrm{~d}$. 


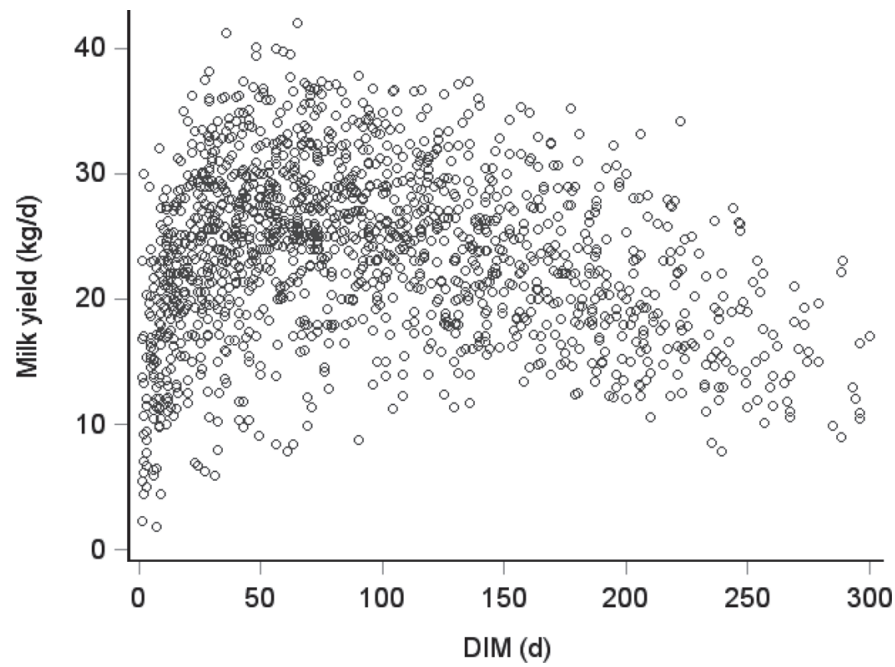

Figure 3. Plot of first-lactation test-day milk yield observations against DIM.

\section{First-Lactation Test-Day Yield (Models 4a, b, and c)}

The relationship between rearing period growth variables and milk yield of primiparous cows was assessed utilizing test-day data from the Norwegian Dairy Herd Recording System. Only heifers calving from October 2013 to October 2014 who had been mated with NR AI sires were included. Heifers that gave birth to twins were excluded. Test-day observations after 305 DIM were deleted. Animals without test-day data (among these an entire herd) were excluded. After imposing these restrictions, the required combined weight and test-day data set consisted of 350 heifers with a total of 1,510 test-day observations (Figure 3). In Figure 3, all these data are plotted over the course of the lactation, depicting a lactation curve that peaks around 50 DIM. The number of test-day observations varied from 1 to 12 per cow, and $41 \%$ of the animals had 5 or more observations.

The following model (model 4a) was used to analyze the test-day data:

$$
\begin{gathered}
Y_{i j k l m}=\mu+\beta_{1} \cdot \mathrm{LEG}_{1}+\cdots+\beta_{3} \cdot \mathrm{LEG}_{3}+S_{i} \\
+\mathrm{AFC}_{j}+\beta_{4} \cdot X+\mathrm{cow}_{k}+\operatorname{herd}_{l}+e_{i j k l m},
\end{gathered}
$$

where $Y_{i j k l m}$ is 1 observation of test-day milk yield $(\mathrm{kg} / \mathrm{d})$ in the first lactation; $\mu$ is the overall mean; $\beta_{1}$, $\ldots, \beta_{3}$ are fixed regression coefficients of first-, ..., third-order LEG for the lactation curve; $S_{i}$ is the fixed effect of the $i$ th calving season $[i=1, \ldots, 4$; March to May $(\mathrm{n}=97)$, June to August $(\mathrm{n}=135)$, September to November $(\mathrm{n}=59)$, December to February $(\mathrm{n}=59)$ ]; $\mathrm{AFC}_{j}$ is the fixed effect of the $j$ th age at first calving
$(\mathbf{A F C})$ class $(j=1, \ldots, 5 ; \leq 23,24,25,26$, and $\geq 27 \mathrm{mo}$ of age, representing 19,28,21, 14, and $18 \%$ of the animals, respectively); $\beta_{4}$ is the fixed linear regression on the calculated variables of growth (hBW, hBWG, iSIZE, hSIZE, iBW, or iBWG); cow is a random effect of the $k$ th cow $\left[\sim N\left(0, \mathbf{I} \sigma_{\text {cow }}^{2}\right)\right]$; herd is a random effect of the th herd $\left[\sim N\left(0, \mathbf{I} \sigma_{\text {herd }}^{2}\right)\right] ; \mathbf{I}$ are the identity matrices of dimensions $350 \times 350$ for cows and $29 \times 29$ for herds. Finally, $e_{i j k l m}$ is a random error term associated with the $m$ th test-day observation for the $k$ th cow in herd $l$, modeled with heterogeneous and independent variances for 8 periods of lactation (d; $0-7,8-21,22-49,50-77$, 78-105, 106-133, 134-161, >161).

For the iBWG variables, model $4 \mathrm{a}$ was expanded with the term $\beta_{5} \cdot X^{2}$ (i.e., with the second-order term) to check for nonlinearity in the relationship between milk production and individual growth rate (model $4 \mathrm{~b}$ ). To estimate the interaction between AFC and variables of growth, defined as $X$ in model 4a, test-day milk yield data were also analyzed with model 4c:

$$
\begin{aligned}
& Y_{i j k l m}=\mu+\beta_{1} \cdot \mathrm{LEG}_{1}+\cdots+\beta_{3} \cdot \mathrm{LEG}_{3}+S_{i} \\
& +\beta_{4}(\mathrm{AFC} \cdot X)_{j}+\mathrm{cow}_{k}+\operatorname{herd}_{l}+e_{i j k l m},
\end{aligned}
$$

where terms are as defined in model $4 \mathrm{a}$.

The SAS MIXED procedure (SAS/STAT software; SAS Inc., Cary, NC) was used to carry out all analyses. Denominator degrees of freedom of $F$-tests were calculated using Satterthwaite approximation.

\section{RESULTS}

\section{Herd Mean BW}

The overall mean and the fixed LEG of order 1 and 2 were significant $(P<0.005)$, whereas the person who made the heart girth measurements had no significant effect $(P=0.21)$. Figure 4 shows predicted average BW per herd; it illustrates large variation of hBWG and shows that much of this variation was already established at around 10 mo of age. Calculated hBWG from 5 to 10,10 to 15 , and 15 to 21 mo of age varied from 615 to 1,053, 630 to 946 , and 511 to $889 \mathrm{~g} / \mathrm{d}$, respectively. These herd mean calculations (hBWG) were based on 536 heifers with 6 to 44 animals per herd. For the 350 animals with the required combined weight and test-day observations, mean and standard deviation of hBWG variables over the 29 herds are given in Table 1 .

\section{Individual Size Within Herd}

The overall mean and the LEG of order 1 and 2 were significant $(P<0.0001)$. There was a significant effect 


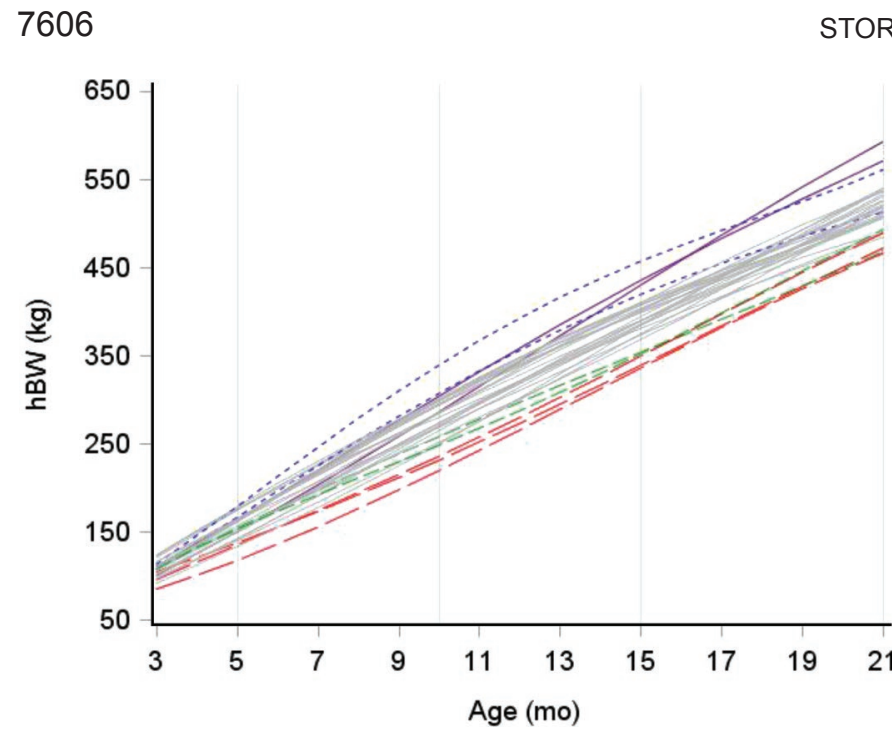

Figure 4. Predicted average BW of heifers per herd (hBW) between 3 and 21 mo of age with model 1. Color version available online.

$(P<0.004)$ of the person who made heart girth measurements, and the largest contrast between recorders was $29.8 \mathrm{~kg}$. The estimated (from the 536 animals) standard deviation (square root of the variance component) for iSIZE and hSIZE was 27.1 and $23.2 \mathrm{~kg}$, respectively. For cows with combined weight and test-day data $(\mathrm{n}=$ 350), mean and standard deviation of iSIZE and hSIZE are given in Table 1.

iBW

The overall mean and the LEG of order 1 and 2 were significant $(P<0.0001)$, and so was the effect of the person who made heart girth measurements $(P<$
Table 1. Predicted (with model 1) average weight gain per herd of heifers ${ }^{1}$ (hBWG) between 5 and 10,10 and 15 , and 15 and 21 mo of age; predicted (with model 2) individual deviates for size (iSIZE) from that predicted for herds (hSIZE); and predicted (with model 3 ) individual $\mathrm{BW}(\mathrm{iBW})$ at $5,10,15$, and $21 \mathrm{mo}$ of age as well as individual BW gain (iBWG)

\begin{tabular}{lccr}
\hline Item & $\mathrm{n}$ & Mean & $\mathrm{SD}$ \\
\hline Model 1 & & & \\
hBWG5-10 (g/d) & 29 & 802 & 100.9 \\
hBWG10-15(g/d) & 29 & 747 & 71.0 \\
hBWG15-21(g/d) & 29 & 681 & 99.8 \\
Model 2 & & & \\
iSIZE (kg) & 350 & 0 & 23.2 \\
hSIZE (kg) & 29 & -2 & 35.1 \\
Model 3 & 350 & 153 & \\
iBW5 (kg) & 350 & 274 & 31.2 \\
iBW10 (kg) & 350 & 387 & 36.9 \\
iBW15 (kg) & 350 & 512 & 43.6 \\
iBW21 (kg) & 350 & 792 & 80.5 \\
iBWG5-10 (g/d) & 350 & 743 & 68.5 \\
iBWG10-15 (g/d) & 350 & 682 & 112.0 \\
iBWG15-21 (g/d) & &
\end{tabular}

${ }^{1}$ Based on the 350 animals from 29 herds that had test-day milk yield data.

$0.0001)$; the largest contrast between recorders was 25.7 $\mathrm{kg}$. Figure 5a illustrates how the model fits to the data, whereas Figure 5b shows that predictions were close to unbiased, with mean-squared error increasing with age (around $5 \%$ of BW for all ages). For cows with combined weight and test-day data, the mean and standard deviation of $\mathrm{iBW}$ and $\mathrm{iBWG}$ are given in Table 1.

Estimated (co)variance parameters of $\sigma_{\beta_{0}}^{2}, \sigma_{\beta_{0} \beta_{1}}, \sigma_{\beta_{1}}^{2}, \sigma_{\beta_{0} \beta_{2}}, \sigma_{\beta_{1} \beta_{2}}$, and $\sigma_{\beta_{2}}^{2}$ were $2,121, \quad 1,086.3$, $1,082.6,2.2,431.1$, and 439.0, respectively. The standard deviation of the error term for the 6 age periods increased with age, from 8 to $27 \mathrm{~kg}$ (Figure 2).
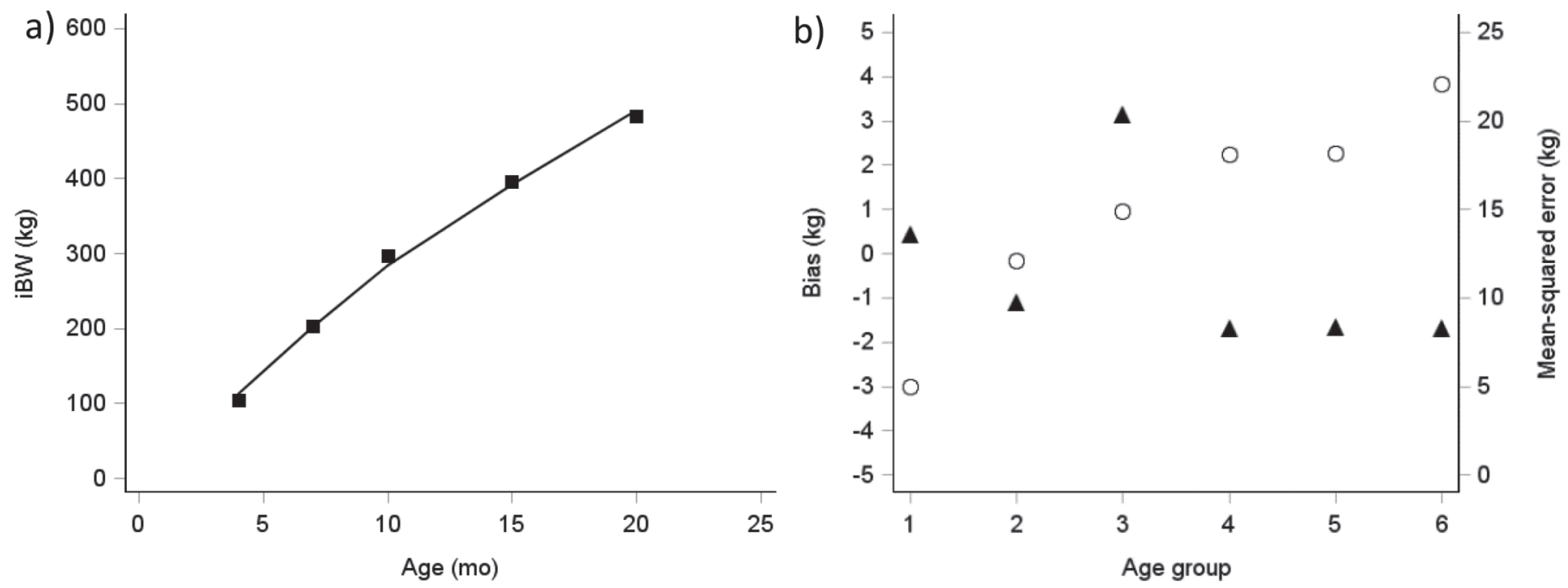

Figure 5. (a) Observed ( $\mathbf{\square})$ and predicted individual BW (iBW; solid line, obtained with model 3; by age) for 1 randomly sampled cow. (b) $\operatorname{Bias}(\mathbf{\Lambda})$ and mean-squared error of prediction $(\bigcirc)$ from model $3 ; 6$ age periods $(<5,5-8,9-12,13-16,17-20$, and $>20$ mo). 
Table 2. $F$-statistics and $P$-values of fixed effects ${ }^{1}$ included in models $4 \mathrm{a}$ and $4 \mathrm{c}$, which are first-lactation test-day models, aimed at estimating main effects of heifer growth variables ( $X$; see Table 1$)$ and age at first calving (AFC, with 5 classes; columns 2 and 3; model 4a) $)^{2}$ or an interaction between the two $(X \times$ AFC, last column; model 4c $)^{2}$

\begin{tabular}{|c|c|c|c|}
\hline \multirow[b]{2}{*}{ Item $^{3}$} & \multicolumn{3}{|c|}{$F$ ( $P$-value $)$} \\
\hline & $X$ & $\mathrm{AFC}$ & $X \times \mathrm{AFC}$ \\
\hline \multicolumn{4}{|l|}{ Model 1} \\
\hline hBWG5-10 & $0.0(0.86)$ & $2.4(0.05)$ & - \\
\hline hBWG10-15 & $0.2(0.64)$ & $2.4(0.05)$ & - \\
\hline hBWG15-21 & $0.4(0.53)$ & $2.4(0.05)$ & - \\
\hline hBWG $5-10 \times \mathrm{AFC}$ & - & - & $2.0(0.09)$ \\
\hline hBWG10-15 × AFC & - & - & $2.1(0.07)$ \\
\hline hBWG15-21 × AFC & - & - & $2.0(0.08)$ \\
\hline \multicolumn{4}{|l|}{ Model 2} \\
\hline iSIZE & $3.0(0.08)$ & $2.6(0.03)$ & - \\
\hline $\mathrm{iSIZE} \times \mathrm{AFC}$ & - & - & $0.6(0.67)$ \\
\hline hSIZE & $0.2(0.65)$ & $2.4(0.05)$ & - \\
\hline $\mathrm{hSIZE} \times \mathrm{AFC}$ & - & - & $0.8(0.53)$ \\
\hline \multicolumn{4}{|l|}{ Model 3} \\
\hline iBW5 & $1.0(0.32)$ & $2.5(0.04)$ & - \\
\hline iBW10 & $1.6(0.21)$ & $2.6(0.04)$ & - \\
\hline iBW15 & $2.6(0.11)$ & $2.7(0.03)$ & - \\
\hline iBW21 & $3.9(0.05)$ & $2.8(0.03)$ & — \\
\hline iBW5 × AFC & - & - & $2.0(0.08)$ \\
\hline $\mathrm{iBW} 10 \times \mathrm{AFC}$ & - & - & $2.2(0.06)$ \\
\hline $\mathrm{iBW} 15 \times \mathrm{AFC}$ & - & - & $2.4(0.04)$ \\
\hline $\mathrm{iBW} 21 \times \mathrm{AFC}$ & - & - & $2.7(0.02)$ \\
\hline iBWG5-10 & $2.2(0.14)$ & $2.7(0.03)$ & - \\
\hline iBWG10-15 & $3.8(0.05)$ & $2.7(0.03)$ & - \\
\hline iBWG15-21 & $2.0(0.16)$ & $2.5(0.05)$ & - \\
\hline iBWG5-10 × AFC & - & - & $2.3(0.04)$ \\
\hline iBWG10-15 × AFC & - & - & $2.8(0.02)$ \\
\hline iBWG15-21 × AFC & - & - & $2.4(0.04)$ \\
\hline
\end{tabular}

${ }^{1}$ Legendre polynomials (LEG1, LEG2, and LEG3; $\left.P<0.0001\right)$ and calving season $(P=0.06-0.31)$.

${ }^{2}$ Models had $\sigma_{\text {cow }}=4.2-4.3, \sigma_{\text {herd }}=3.5-3.7, \sigma_{\text {e minimum }}=2.0-2.1$, and $\sigma_{\text {e maximum }}=8.4 \mathrm{~kg}$, where $\sigma$ is the SD of cow, herd, and heterogeneous error (the latter represented by minimum and maximum values).

${ }^{3}$ Model 1: average weight gain per herd of heifers (hBWG) between 5 and 10,10 and 15, and 15 and 21 mo of age. Model 2: individual deviates for size (iSIZE) from that predicted for herds (hSIZE). Model 3: individual $\mathrm{BW}(\mathrm{iBW})$ at 5, 10, 15, and 21 mo of age as well as individual BW gain (iBWG).

\section{First-Lactation Test-Day Yield}

Table 2 gives the relevant results on how rearing period growth affects first-lactation test-day milk yield. When considered as main effects, both iBW21 and iBWG10-15 regressed significantly on milk yield $(P<$ 0.05 ), whereas the main effect of AFC in general was significant irrespective of which growth variable was included in the calculations. Furthermore, the test statistics improved for a model with interaction between $\mathrm{AFC}$ and variables of growth, and mostly so for iBW21 and iBWG10-15.
Modeling with both a first- and second-order fixed regression on iBWG variables (model $4 \mathrm{~b}$ ) resulted in $P$ values of 0.058 and 0.085 , respectively, for iBWG10-15 (Table 3); first- and second-order regression coefficients are also given in Table 3. The corresponding leastsquares means of milk yield for an interval of iBWG10 15 values shown in Figure 6 suggest that $830 \mathrm{~g} / \mathrm{d}$ is the optimum postpubertal growth rate.

For iBWG10-15 in the interaction model (model 4c), the estimated least-squares means of AFC at near-peak lactation (50 DIM) are given in Table 4. The estimate was most pronounced for an AFC of 26 mo but was

Table 3. First- and second-order regression coefficients $\left(\beta_{4}\right.$ and $\left.\beta_{5}\right)$ of individual BW gain (iBWG) variables $(5-10,10-15$, and $15-21$ mo of age) on test-day milk yield in model $4 \mathrm{~b}$

\begin{tabular}{lcccc}
\hline Variable & $\beta_{4}$ & $P$-value & $\beta_{5}$ & $P$-value \\
\hline iBWG5-10 & 0.037 & 0.427 & -0.000020 & 0.505 \\
iBWG10-15 & 0.103 & 0.058 & -0.000060 & 0.085 \\
iBWG15-21 & 0.015 & 0.016 & -0.000008 & 0.593 \\
\hline
\end{tabular}


Table 4. First-lactation test-day milk yield (kg) at 50 DIM (near peak), estimated least squares means (LSM) for age at first calving (AFC, mo) at average individual BW gain from 10 to 15 mo of age, ${ }^{1}$ and LSM contrasts ${ }^{2}$

\begin{tabular}{|c|c|c|c|c|c|}
\hline \multirow[b]{2}{*}{$\mathrm{AFC}$} & \multirow[b]{2}{*}{ LSM } & \multicolumn{4}{|c|}{ LSM contrasts ( $P$-value) } \\
\hline & & 24 & 25 & 26 & $\geq 27$ \\
\hline$\leq 23$ & 24.8 & $-1.2(0.11)$ & $-2.1(0.01)$ & $-2.9(0.00)$ & $-1.7(0.08)$ \\
\hline$\overline{24}$ & 26.0 & - & $-0.9(0.25)$ & $-1.7(0.06)$ & $-0.5(0.58)$ \\
\hline 25 & 26.9 & - & - & $-0.8(0.37)$ & $0.4(0.67)$ \\
\hline 26 & 27.7 & - & & - & $1.2(0.22)$ \\
\hline$\geq 27$ & 26.5 & - & & - & - \\
\hline
\end{tabular}

also high for $25 \mathrm{mo}$. Both estimates $(2.9$ and $2.1 \mathrm{~kg}$, respectively) were significantly $(P<0.05)$ higher than that at 23 mo of age (Table 4$)$. Estimated regression coefficients for the interaction between AFC and iBWG from 10 to 15 mo of age (iBWG10-15) are given in Table 5.

Calving season did not significantly $(P=0.06-0.31)$ affect production, whereas LEG of order 1,2 , and 3 generally differed from zero $(P<0.0001$; Table 2$)$. The standard deviation of cow and herd was 4.2 to 4.3 and 3.5 to $3.7 \mathrm{~kg}$ of milk/d, respectively, and the standard deviation for the error term of the 8 lactation-day periods was maximum $8.4 \mathrm{~kg}$ just after calving and minimum $2.0 \mathrm{~kg}$ for $\mathrm{d} 78$ to 105.

\section{DISCUSSION}

Heifer growth rates varied considerably between herds (Figures 2 and 4). However, not surprisingly, the

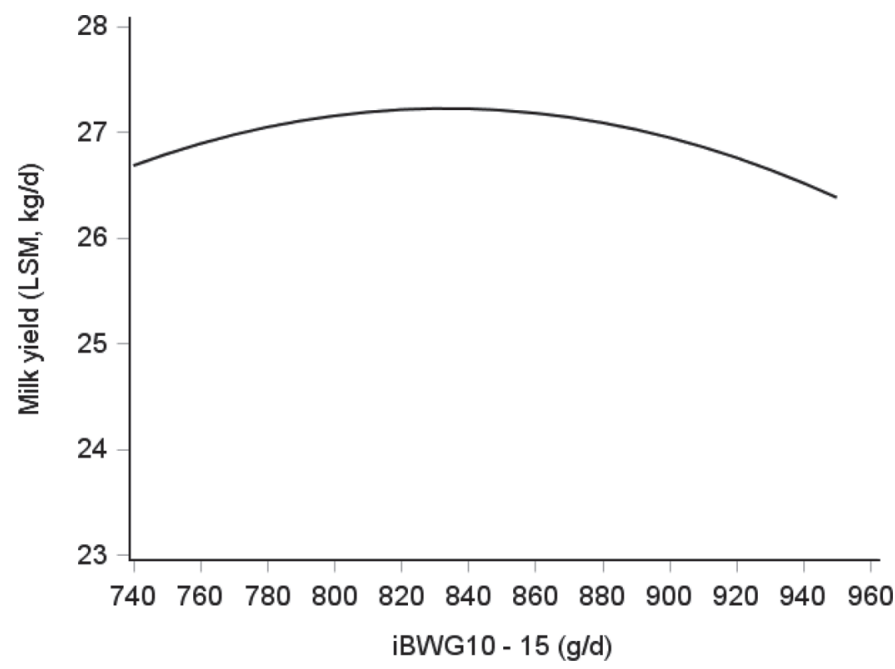

Figure 6. Least squares means of milk yield $(y)$ when individual BW gain between 10 and 15 mo of age (iBWG10-15; x) varied from $743 \mathrm{~g} / \mathrm{d}$ (mean) to $949 \mathrm{~g} / \mathrm{d}$ ( $+3 \mathrm{SD}$; model $4 \mathrm{~b})$. The equation was as follows: $y=-15.809+0.103 x-0.00006 x^{2}(P=0.058$ and 0.085 , respectively). rate at which the average animal in a given herd grows had little bearing on first-lactation milk yield (Table 2 , column 2 , model $1, \mathrm{hBWG}$ ). Interestingly, much of the variation in hBWG was already established at the onset of puberty (Figure 4). The variation is likely not attributable to genetic differences because the genetic material is relatively similar in all NR herds. This is because AI use is more than $85 \%$ and highly regulated; all farms have to use $40 \%$ test bulls, and the use of proven bulls is determined using mating plan software (Geno SA, Hamar, Norway) that takes into consideration the relationship between the male and the female. Besides, individual size differences are largely cancelled from calculating averages. Thus, herd mean differences will mainly reflect herd-specific management practices and decisions. Briefly summarizing information from the questionnaires, it was evident that preweaning practices varied substantially between farms. Heifer feeding practices, on the other hand, followed a uniform, mainly roughage-based regimen, with only restricted use of concentrate. Moreover, the decision on when to start insemination was based on heifers' age (i.e., from 13 to $15 \mathrm{mo}$ ), whereas size was taken into consideration only when animals were small for their age. Use of pasture again varied considerably, but all farmers used available natural pasture for their young stock from 6 mo of age and for a period from 8 up to 12 wk each grazing season. Group dynamics, including competition for available resources and the regrouping of animals,

Table 5. First-lactation test-day milk yield $(\mathrm{kg})$ and estimated regression coefficients $\left(\beta_{4}\right)$ for the interaction between age at first calving (AFC, mo) and predicted individual BW gain from 10 to 15 mo of age ${ }^{1}$

\begin{tabular}{ll}
\hline AFC & $\beta_{4}(P$-value $)$ \\
\hline$\leq 23$ & $0.007(0.11)$ \\
24 & $0.009(0.06)$ \\
25 & $0.010(0.03)$ \\
26 & $0.011(0.02)$ \\
$\geq 27$ & $0.010(0.05)$ \\
\hline
\end{tabular}

${ }^{1}$ Results are from the interaction model (model 4c). 
also add to the herd-specific management (Estevez et al., 2007).

The size of an individual animal within the herd (iSIZE) had a near-significant effect on subsequent milk yield $(P=0.08$; Table 2 , column 2 , model 2$)$. This suggests that it is beneficial to be large, and size has long been identified as one driver of increased milk production (see, e.g., Syrstad, 1966; Markusfeld and Ezra, 1993). Moreover, although obtained as a regression, this result compares favorably with the positive genetic correlation that has previously been demonstrated between body size and milk yield in dairy cows (Ahlborn and Dempfle, 1992; Pryce and Harris, 2006).

We obtained the largest $F$-values for the main effect of growth when milk yield was regressed on heifers' iBW and individual growth rate (Table 2, column 2, model 3)-more specifically, from iBW21 and ADG during the postpubertal period, iBWG10-15 $(P=0.05$ for both). This would be expected because variables based on individual growth will be spread out more than iSIZE because the former is affected both by individual size and by herd-specific environmental effects. Furthermore, because BW at 21 mo of age largely is determined by growth rate from 5 to 21 mo of age rather than by $\mathrm{BW}$ at 5 mo alone, which here ideally should have been replaced by birth weight, the effect of BW is actually an effect of ADG, or growth rate. At a predefined age, iBW (iBW5, ..., iBW21) is basically a weighted mean of the intercept solution for animal $k$ and the first- and second-order solutions for the same animal ( $\beta_{1 k}$ and $\beta_{2 k}$, respectively). Thus, at low ages iBW is determined mainly by the intercept solution for an animal $\left(\beta_{0 k}\right)$, whereas at high ages iBW is more influenced by the higher order solutions for the animal $\left(\beta_{1 k}\right.$ and $\left.\beta_{2 k}\right)$. The biological implications are that iBW21 more expresses ADG over the whole range from 5 to 21 mo of age, whereas iBWG variables are more specific for their respective age intervals and allow the estimation of age-specific effects of growth. Thus, iBWG variables were preferred, and our findings pointed toward an optimal postpubertal iBWG10-15 of $830 \mathrm{~g} / \mathrm{d}$ (Figure 6) that would optimize first-lactation yield. It should be noted that the same curvilinear relationship also persisted when we omitted AFC from the statistical model (model 4b; $P=0.054$ and 0.071). This implies that the curvilinearity does not rely on the statistical correction for AFC. Physiologically, the importance of this period would be consistent with the increased growth and development of the mammary parenchyma that occurs from the onset of puberty. From this stage on, the ductal tree lengthens, branches, and extends with an increasing number of terminal ductal lobular units further and upward into the collagenous stroma in response to (mainly) estradiol from the ovaries during the follicular phase of each estrous cycle (see, e.g., Capuco and Ellis, 2013). It would also be compatible with the positive association between a high postpubertal growth rate and first-lactation yield reported by Macdonald et al. (2005) and in a recent comparable study by Krpálková et al. (2014).

The main effect of prepubertal growth rate (iBWG510) on first-lactation yield in the present material was not significant $(P=0.14$; Table 2 , column 2 , model 3 ), which is in line with the findings of Capuco et al. (1995) and Waldo et al. (1998) but contrary to much of the early literature. Swanson (1960) reported that fattened, faster growing heifers had lower first-lactation yield than their nonfattened identical twins when both groups were bred to calve at 24 mo. Later, Little and Kay (1979) and Sejrsen et al. (1982) concluded that high growth rates due to a high plane of nutrition before puberty could compromise mammary development and reduce subsequent milk yield. Numerous studies on the influence of nutrition on mammary development in heifers (see, e.g., review by Sejrsen, 1994) then followed. Based on earlier Danish studies, Sejrsen et al. (2000) further demonstrated a quadratic response in firstlactation milk yield to increased prepubertal growth rate. This suggested that an optimal prepubertal ADG exists, which the authors assumed would increase in a dynamic manner with increasing genetic potential for milk yield from $650 \mathrm{~g} / \mathrm{d}$ in the $1980 \mathrm{~s}$ to around $750 \mathrm{~g} / \mathrm{d}$ during the first decade of the 2000s. A similar curvilinear relationship, suggesting an optimal prepubertal ADG of around $800 \mathrm{~g} / \mathrm{d}$, was later demonstrated in a metastudy based on results from the 1990s (Zanton and Heinrichs, 2005). In the present study, however, there was no such quadratic response in milk yield to changes in prepubertal ADG (Table 3). A likely solution to the often-conflicting results on the relationship between prepubertal growth rate and mammary development was presented by Meyer et al. (2006a,b) and Daniels et al. (2009), who showed that whereas the mammary fat pad responded to the increased plane of nutrition and accelerated growth rate in prepubertal heifers, the parenchyma did not; instead, there was an effect of age of the animal. Although the relationship between growth rate and milk yield is most likely a dynamic one, an optimal prepubertal ADG of $750 \mathrm{~g} / \mathrm{d}$ around 2010 (Sejrsen et al., 2000) was probably an underestimate. The rather moderate growth rate of the majority of the heifers in the present study during the prepubertal phase $(792 \mathrm{~g} / \mathrm{d}$; Table 1) would have allowed ample time for the animals to reach puberty, to go through an average of 6 to 7 estrous cycles, and thus for the mammary gland to develop properly before the animals were bred. However, for the highest individual growth rates, and noting that individual growth rates in the 
2 successive periods (5-10 and $10-15$ mo of age) were highly correlated $(\mathrm{r}=0.97)$, age becomes a limiting factor, explaining our finding of a curvilinear relationship between ADG from 10 to 15 mo of age and subsequent milk yield.

For iBWG variables, we identified a general significant main effect of AFC (Table 2, column 3) and significant interactions with individual growth variables $(P<0.05$; Table 2 , column 4). Again, most information could be obtained from the interactions with postpubertal growth rate (iBWG10-15; $P=0.02$ ). In the interaction model (model 4c), heifers with an AFC of 26 mo produced about $3 \mathrm{~kg}$ more milk/d than heifers with an AFC of $\leq 23$ mo of age, whereas an AFC $\geq 27$ mo again led to reduced milk production (Table 4). The former suggests that NR heifers are punished yieldwise in the first lactation if they calve too early; this agrees with previous findings in Holsteins in the United States (Ettema and Santos, 2004), Belgium (Froidmont et al., 2013), the United Kingdom (Wathes et al., 2014), and the Czech Republic (Krpálková et al., 2014). Note that in the interaction model, the regression coefficients for the interaction between AFC and iBWG10-15 were consistently reduced for the youngest age groups (Table 5) as they were for iBWG5-10 and iBWG15-21 (result not shown). Moreover, the 3 growth variables were all highly correlated $(>0.63)$. This implies that milk yield will be less affected by growth rate in the lowest AFC class (i.e., when animals are compromised by not being fully mature at calving). In that case, animals would have to partition more energy to their own growth at the expense of milk yield. This would mean that primiparous cows should not calve too early and supports previous conclusions that the AFC should not be lower than 23 mo of age (see, e.g., review by Wathes et al., 2014). Alternatively, the partitioning of energy could have been explored by regressing milk yield on the difference between postcalving and mature weights and on our growth rate variables. However, neither postcalving weight nor mature weight were recorded in this field material.

Despite the historical recommendation to breed replacement heifers at $15 \mathrm{mo}$ in order for them to calve at $24 \mathrm{mo}$, the fact that most farmers aim for a calving age of $24 \mathrm{mo}$, and the fact that $28 \%$ of the animals did calve at $24 \mathrm{mo}$, milk production of primiparous cows in this study peaked at an AFC of 26 mo. In comparison, concurrent first-lactation yield peaked at 23 to $25 \mathrm{mo}$ in UK Holsteins (Wathes et al., 2014) and at $>25$ mo in the Czech Republic (Krpálková et al., 2014). The age 26 mo should not be viewed as optimum; rather, it is a consequence of the moderate growth rate of $770 \mathrm{~g} / \mathrm{d}$ from 5 to 15 mo of age (i.e., through puberty and until successful insemination). Moreover, the correlation between BW15 and AFC was -0.3, illustrating that AFC depends on growth. Thus, it should be possible to reduce $\mathrm{AFC}$ by utilizing the knowledge obtained: that the optimal growth rate for first-lactation yield in NR is dynamic, increases with selection over time, and is at present $830 \mathrm{~g} / \mathrm{d}$ in the postpubertal period. Utilizing simple proportionality and results from Figure 6 and Table 1, prepubertal ADG ideally should be $879 \mathrm{~g} / \mathrm{d}$. This would take into account that animal growth rate is higher at low ages and that high prepubertal growth rate had no negative effect on milk yield.

That milk yield declined at $\mathrm{AFC} \geq 27$ mo suggests that NR heifers are also punished if they calve too late. Again, this is in line with previous findings in Holsteins (Froidmont et al., 2013; Wathes et al., 2014). It may look like a paradox because animals should then be larger at first calving. Interestingly, we found a significant first-order regression coefficient $\left(\beta_{1}=-0.072 ; P\right.$ $=0.002$ ) between iSIZE and AFC (Figure 7), a highly significant regression coefficient $\left(\beta_{1}=-0.219 ; P<\right.$ 0.0001 ) between iBW21 and AFC (Figure 8), and, not surprisingly, a correlation of 0.63 between iSIZE and iBW21. Animals with the smallest iSIZE values would be either animals that are genetically small or the losers in the herd, and the latter would probably be comparable with the underfed, poor performers described by Wathes et al. (2008). But, according to Figure 8, the animals that calve the latest are the ones that weigh the least at 21 mo of age (iBW21). The iBW21 includes herd-specific effects, and herds with a low average growth rate (hBWG; Figure 4) were overrepresented in the group of animals with an AFC $\geq 27$ mo (64 animals). The proportion of these animals in herds with high (14 herds) and low (15 herds) hBW21 values was 33 and $67 \%$, respectively. The 64 animals were also overrepresented among animals with low postpubertal growth rate (iBWG10-15) values, which is clearly illustrated by the finding that $72 \%$ had lower iBWG10-15 values than the average for the 350 cows with combined weight and test-day data. This means that the decline in milk yield for animals with $\mathrm{AFC} \geq 27$ mo is explained by a too-low ADG. In Figure 8, inferences were made from iBW21 because BW at calving was unavailable. If we had had calving weights, we might have been able to find an optimum size, such as that estimated for NR by Syrstad (1966) and that discussed in a review on Holstein replacement heifers by Hoffman (1997). However, when using iBW21 as a proxy for calving weight and omitting AFC from the model (model 4b), we could find neither a linear $(P=0.11)$ nor a curvilinear relationship (iBW21 and iBW21 ${ }^{2} ; P=0.14$ and 0.18 ). Because calving weight was not observed in the field, the growth rates until calving could not be calculated, and the final rate examined was that between 15 and 21 


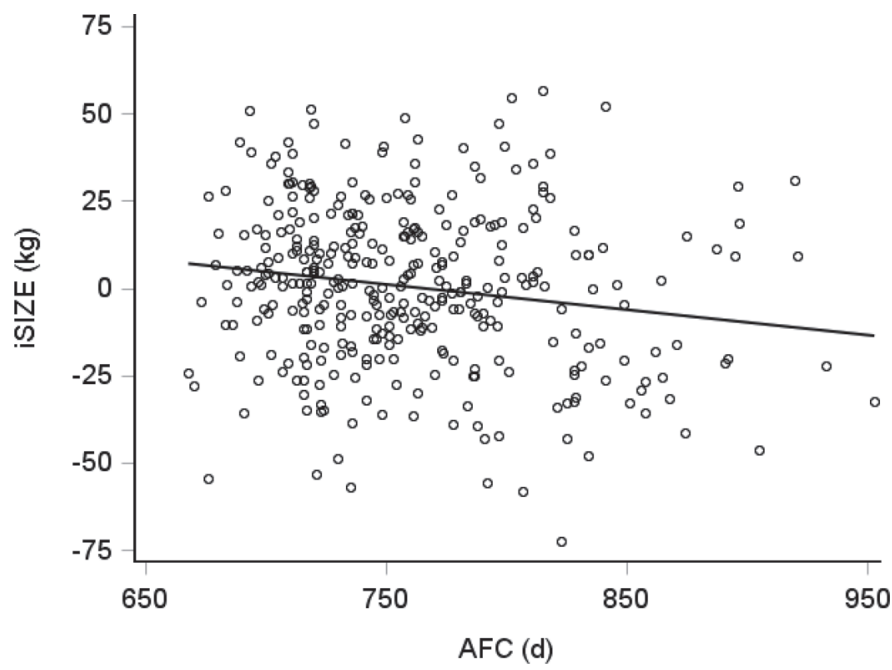

Figure 7. Predicted size of an individual animal within the herd (iSIZE; $y$ ) adjusted for the random effect of herd (model 2), plotted against age at first calving (AFC; $x)$. The equation was as follows: $y=$ $55.456-0.073 x(P=0.002)$.

mo of age (iBWG15-21), which was not significant $(P$ $=0.16$; Table 2) when treated as a main effect.

\section{CONCLUSIONS}

Under field conditions in Norway, growth rate in the postpubertal period from 10 to 15 mo of age seems to have a significant bearing on first-lactation yield of $\mathrm{NR}$, with a current optimum of $830 \mathrm{~g} / \mathrm{d}$. This is around $90 \mathrm{~g} / \mathrm{d}$ higher than the corresponding present average growth rate. The importance of the postpubertal period would be consistent with the increased growth and development of the mammary parenchyma that occurs from the onset of puberty. The optimum is likely dynamic, increasing from selection over time, and should be proportionally adjusted in the prepubertal period to account for a higher ADG at lower ages. By adopting such a rearing practice to meet the requirements of the genetically improved NR heifer of today, heifers in an average Norwegian dairy herd can both optimize production in their first lactation and enter the milking herd at an earlier age than the current average of 24.8 mo.

\section{ACKNOWLEDGMENTS}

The authors acknowledge the farmers for their willingness to participate and Tilde Sæther, Benjamin Eliassen, and Topp Team Fôring (Tine SA, Ås, Norway) for excellent on-farm recording. We also thank the Norwegian Dairy Herd Recording System (Ås, Norway)

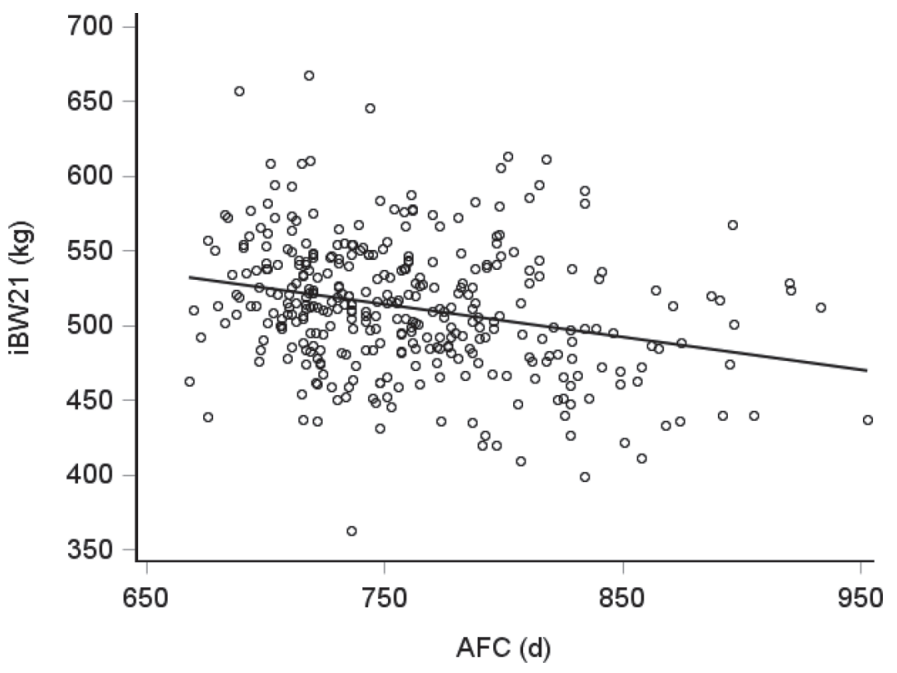

Figure 8. Predicted individual BW at 21 mo of age (iBW21; obtained with model $3 ; y)$ plotted against age at first calving (AFC; $x$ ). The equation was as follows: $y=678.293-0.219 x(P<0.0001)$.

for access to data and the Research Council of Norway (Oslo, Norway) for funding (Project number 199448).

\section{REFERENCES}

Ahlborn, G., and L. Dempfle. 1992. Genetic parameters for milk production and body size in New Zealand Holstein-Friesian and Jersey. Livest. Prod. Sci. 31:205-219. https://doi.org/10.1016/03016226(92)90018-Y

Bekkevoll, M., and A. Helberg. 2009. Heifer growth characteristics in dairy herds with high milk yield (in Norwegian). MS Thesis. Department of Animal and Aquacultural Sciences, Norwegian University of Life Sciences, Ås, Norway.

Brickell, J. S., M. M. McGowan, and D. C. Wathes. 2009. Effect of management factors and blood metabolites during the rearing period on growth in dairy heifers on UK farms. Domest. Anim. Endocrinol. 36:67-81. https://doi.org/10.1016/j.domaniend.2008.10.005.

Capuco, A. V., and S. E. Ellis. 2013. Comparative aspects of mammary gland development and homeostasis. Annu. Rev. Anim. Biosci. 1:179-202. https://doi.org/10.1146/annurevanimal-031412-103632

Capuco, A. V., J. J. Smith, D. R. Waldo, and C. E. Rexroad Jr.. 1995. Influence of prepubertal dietary regimen on mammary growth of heifers. J. Dairy Sci. 78:2709-2725. https://doi.org/10.3168/jds. S0022-0302(95)76902-8.

Daniels, K. M., M. L. McGilliard, M. J. Meyer, M. E. Van Amburgh, A. V. Capuco, and R. M. Akers. 2009. Effects of BW and nutrition on histological mammary development in Holstein heifers. J. Dairy Sci. 92:499-505. https://doi.org/10.3168/jds.2008-1007.

Estevez, I., I.-L. Andersen, and E. Nævdal. 2007. Group size, density and social dynamics in farm animals. Appl. Anim. Behav. Sci. 103:185-204. https://doi.org/10.1016/j.applanim.2006.05.025.

Ettema, J. F., and J. E. P. Santos. 2004. Impact of age at calving on lactation, reproduction, health, and income in first-parity Holsteins on commercial farms. J. Dairy Sci. 87:2730-2742. https:// doi.org/10.3168/jds.S0022-0302(04)73400-1.

Foldager, J., and K. Sejrsen. 1991. Rearing intensity in dairy heifers and the effect on subsequent milk production. Report 693. Natl. Inst. Anim. Sci., Foulum, Denmark.

Froidmont, E., P. Mayeres, P. Picron, A. Turlot, V. Planchon, and D. Stilmant. 2013. Association between age at first calving, year 
and season of first calving and milk production in Holstein cows. Animal 7:665-672. https://doi.org/10.1017/S1751731112001577.

Geno SA. 2015. Årsberetning og regnskap 2015. Accessed Sep. 9, 2016. http://viewer.zmags.com/publication/d0639eeb\#/d0639eeb/14.

Hoffman, P. C. 1997. Optimum body size of Holstein replacement heifers. J. Anim. Sci. 75:836-845. https://doi.org/10.2134/ jas1997.753836x.

Krpálková, L., V. E. Cabrera, M. Vacek, M. Stipková, L. Stádnik, and P. Crump. 2014. Effect of prepubertal and postpubertal growth and age at first calving on production and reproduction traits during the first 3 lactations in Holstein dairy cattle. J. Dairy Sci. 97:3017-3027. https://doi.org/10.3168/jds.2013-7419.

Little, W., and R. M. Kay. 1979. The effects of rapid rearing and early calving on the subsequent performance of dairy heifers. Anim. Prod. 29:131-142. https://doi.org/10.1017/S0003356100012228.

Macdonald, K. A., J. W. Penno, A. M. Bryant, and J. R. Roche. 2005. Effect of feeding level pre- and post-puberty and body weight at first calving on growth, milk production, and fertility in grazing dairy cows. J. Dairy Sci. 88:3363-3375. https://doi.org/10.3168/ jds.S0022-0302(05)73020-4.

Markusfeld, O., and E. Ezra. 1993. Body measurements, metritis, and postpartum performance of first lactation cows. J. Dairy Sci. 76:3771-3777. https://doi.org/10.3168/jds.S0022-0302(93)777206.

Meyer, M. J., A. V. Capuco, D. A. Ross, L. M. Lintault, and M. E. Van Amburgh. 2006a. Developmental and nutritional regulation of the prepubertal bovine mammary gland: I. Parenchyma and fat pad mass and composition. J. Dairy Sci. 89:4289-4297. https:// doi.org/10.3168/jds.S0022-0302(06)72475-4.

Meyer, M. J., A. V. Capuco, D. A. Ross, L. M. Lintault, and M. E. Van Amburgh. 2006b. Developmental and nutritional regulation of the prepubertal bovine mammary gland: II. Epithelial cell proliferation, parenchymal accretion rate, and allometric growth. J. Dairy Sci. 89:4298-4304. https://doi.org/10.3168/jds.S00220302(06) 72476-6.

Pryce, J. E., and B. L. Harris. 2006. Genetics of body condition score in New Zealand dairy cows. J. Dairy Sci. 89:4424-4432. https:// doi.org/10.3168/jds.S0022-0302(06)72490-0.
Schaeffer, L. R. 2016. Random regression models. Accessed Dec. 29, 2016. http://www.aps.uoguelph.ca/ lrs/BOOKS/rrmbook.pdf.

Sejrsen, K. 1994. Relationships between nutrition, puberty and mammary development in cattle. Proc. Nutr. Soc. 53:103-111.

Sejrsen, K., J. T. Huber, H. A. Tucker, and R. M. Akers. 1982. Influence of nutrition on mammary development in pre- and postpubertal heifers. J. Dairy Sci. 65:793-800. https://doi.org/10.3168/jds. S0022-0302(82)82268-6.

Sejrsen, K., and S. Purup. 1997. Influence of prepubertal feeding level on milk yield potential of dairy heifers: A review. J. Anim. Sci. 75:828-835.

Sejrsen, K., S. Purup, M. Vestergaard, and J. Foldager. 2000. High BW gain and reduced bovine mammary growth: Physiological basis and implications for milk yield potential. Domest. Anim. Endocrinol. 19:93-104. https://doi.org/10.1016/S0739-7240(00)00070-9.

Swanson, E. W. 1960. Effect of rapid growth with fattening of dairy heifers on their lactational ability. J. Dairy Sci. 43:377-382 https://doi.org/10.3168/jds.S0022-0302(60)90172-7.

Syrstad, O. 1966. Studies on dairy herd records. IV. Estimates of phenotypic and genetic parameters. Acta Agric. Scand. Anim. Sci. 16:90-92. https://doi.org/10.1080/00015126609434169.

Waldo, D. R., A. V. Capuco, and C. E. Rexroad Jr.. 1998. Milk production of Holstein heifers fed either alfalfa or corn silage diets at two rates of daily gain. J. Dairy Sci. 81:756-764. https://doi org/10.3168/jds.S0022-0302(98)75632-2.

Wathes, D. C., J. S. Brickell, N. E. Bourne, A. Swali, and Z. Cheng. 2008. Factors influencing heifer survival and fertility on commercial dairy farms. Animal 2:1135-1143. https://doi.org/10.1017/ S1751731108002322.

Wathes, D. C., G. E. Pollott, K. F. Johnson, H. Richardson, and J. S. Cooke. 2014. Heifer fertility and carry over consequences for life time production in dairy and beef cattle. Animal 8(Suppl. 1):91104. https://doi.org/10.1017/S1751731114000755.

Zanton, G. I., and A. J. Heinrichs. 2005. Meta-analysis to assess effect of prepubertal average daily gain of Holstein heifers on firstlactation production. J. Dairy Sci. 88:3860-3867. https://doi. org/10.3168/jds.S0022-0302(05)73071-X. 